\title{
Educação ambiental: desafios e perspectivas no contexto da Educação Básica
}

\section{Environmental education: challenges and perspectives in the context of basic education}

Tainá Silva Candido Toscan - Mestre em Educação pela Universidade do Extremo Sul Catarinense (UNESC). Doutoranda em Ciências Ambientais no Programa de PósGraduação em Ciências Ambientais da UNESC. E-mail: tainacandido1@hotmail.com

\section{Resumo}

O presente estudo apresenta um panorama do que tem sido pesquisado nos últimos quatro anos (2016-2020) sobre a Educação Ambiental no contexto da Educação Básica. Nesse sentido, objetivou, por meio de revisão bibliográfica, sintetizar publicações na área, identificando as percepções dos autores sobre o tema e o lugar da EA no contexto educacional hoje. Para tanto, a partir de Bardin (2004), categorias foram pensadas e organizadas a fim de sistematizar os dados, a saber: representações dos professores sobre EA e suas práticas; inserção da EA crítica na educação básica e desafios; EA e a formação de professores e EA e políticas educacionais. Entende-se que o lugar da EA no contexto da Educação Básica ainda está envolto em certa nebulosidade, repleto de desafios a serem superados, mesmo com avanços, conquistas e abrangência teórica sobre a EA explicitada como necessidade em todos os níveis de ensino.

\section{Palavras-chave}

Educação Ambiental. Educação Básica. Prática Docente. Desafios.

\section{Abstract}

The present study presents an overview of what has been researched in the last four years (2016-2020) on Environmental Education in the context of Basic Education. In this sense, it aimed, through a bibliographic review, to synthesize publications in the area, identifying the authors' perceptions about the theme and the place of EE in the educational context today. Therefore, from Bardin (2004), categories were thought and organized in order to systematize the data, namely: teachers' representations about EE and its practices; insertion of critical EA in basic education and challenges; EA and teacher training and EA and educational policies. It is understood that the place of $\mathrm{EE}$ in the context of Basic Education is still enveloped in a certain cloudiness, full of challenges to be overcome, even with advances, achievements and theoretical scope on EE explained as a necessity at all levels of education.

\section{Keywords}

Environmental education. Basic education. Teaching Practice. Challenges. 


\section{INTRODUÇÃO}

A Educação Ambiental (EA) foi inserida na pauta das discussões na comunidade escolar a partir da década de 1970, período marcado por conferências e reuniões internacionais relacionadas ao meio ambiente, como, por exemplo, a I Conferência Internacional sobre Meio Ambiente, realizada em 1972 (Estocolmo, Suécia); o Seminário Internacional de Educação Ambiental em 1975 (Belgrado, Iugoslávia) e a Conferência em Tbilisi de 1977 (Geórgia).

Os desdobramentos do debate internacional levaram o Governo Federal a criar, em 1992, o Ministério do Meio Ambiente. Naquele ano, também foi realizada a II Conferência Internacional das Nações Unidas sobre o Meio Ambiente e Desenvolvimento (RIO-92), culminando no fortalecimento das políticas ambientais nacionais e internacionais. Dentre as políticas nacionais relacionadas ao meio ambiente, destaca-se a Lei no 9.795/1999, sancionada no dia 27 de abril (BRASIL, 1999), implicando também nos documentos que norteiam a Educação Básica no Brasil, reelaborados a fim de abranger a EA como tema transversal. A proposta deste estudo não é descrever detalhadamente o caminho trilhado pela EA e suas conquistas, mas acentuo que, mesmo com avanços e abrangência teórica sobre a EA explicitada como necessidade em todos os níveis de ensino, seu lugar no contexto da Educação Básica ainda está situado sob certa nebulosidade. Nesse sentido, evidente está a necessidade de apresentar um panorama do que tem sido pesquisado nos últimos anos sobre a EA no contexto da Educação Básica. Portanto, por meio de revisão bibliográfica, o objetivo foi analisar os estudos publicados na área da Educação Básica referentes à educação ambiental; identificar as percepções dos autores sobre o tema e o lugar da EA no contexto educação básica.

A revisão na literatura partiu de buscas em duas bases de dados, a saber: Portal de Periódicos da CAPES e Google Acadêmico, com o intuito de selecionar estudos mais recentes, do período de 2016 a 2020, sobre a EA no contexto da Educação Básica, por meio dos descritores: "educação ambiental" e "educação básica". A pesquisa nas bases, tendo como critério apenas os artigos que discorriam sobre os dois temas, totalizou oito artigos, apresentados no decorrer deste estudo. Vale destacar que, segundo o critério estabelecido, não foram encontrados artigos publicados nos anos de 2019 e 2020.

No portal de periódicos da CAPES, foram localizados três estudos, sendo estes: Representações de ambiente e educação ambiental: implicações na práxis educativa de professores de ensino fundamental em Moju, PA, Brasil (PINHO et al., 2017); Formações continuadas em educação ambiental: características e limitações (MOTA, 2017) e A inserção 
da educação ambiental crítica na escola via extensão universitária (FIGUEIRA; LIMA; SELLES, 2018).

O estudo de Pinho et al. (2017) foi investigar as representações de ambiente e EA de docentes em uma escola municipal de ensino fundamental no Pará, discutindo como essas representações refletem no fazer pedagógico desses professores. O artigo de Mota (2017) trata da pesquisa bibliográfica, a qual apresenta características e desafios das formações iniciais e continuadas dos profissionais da educação, mais especificamente, dos educadores ambientais. Já o de Figueira, Lima e Selles (2018) identifica limites e possibilidades da inserção da vertente crítica da EA na Educação básica, avaliando a inserção da EA, mediada por um projeto de extensão universitária, em duas escolas públicas municipais do Rio de Janeiro.

No Google Acadêmico, foram selecionados cinco artigos seguindo os critérios estabelecidos para este estudo. O primeiro, denominado As políticas de educação ambiental e suas repercussões sobre o planejamento da educação básica no ensino público brasileiro (ARAGÃO, 2016), fundamenta-se no referencial teórico da EA crítica para analisar a repercussão das políticas de EA no Brasil. O segundo estudo, Concepscôes e atividades docentes de Educação Ambiental e seus desdobramentos na formação de alunos da educação básica (ARAÚJO; OLIVEIRA, 2017), analisa as concepções e atividades realizadas por docentes em EA, buscando compreender como essas práxis se efetivam e quais os seus impactos na formação dos discentes. Já o terceiro, denominado Uma breve reflexão sobre os desafios da Educação Ambiental no ensino formal brasileiro (ARAÚJO; LAMIM-GUEDES JÚNIOR, 2017), buscou, por meio de pesquisa bibliográfica, refletir sobre os desafios da EA no ensino formal, respondendo às seguintes questões: como fazer que a adoção de temas transversais seja eficiente? Como fazer EA nas escolas e universidades? Que experiências exitosas temos no Brasil? Intitulado $A$ abordagem da Educação Ambiental nos PCNS, nas DCNS e na BNCC (BRANCO; ROYER; BRANCO, 2018), o quarto trabalho avalia a EA no Brasil, dando ênfase na legislação, na organização e no papel do currículo e a abordagem da EA nos documentos norteadores: Parâmetros Curriculares Nacionais (PCN), Diretrizes Curriculares Nacionais (DCN) e Base Nacional Comum Curricular (BNCC). Por fim, de Frizzo e Carvalho (2018), denominado Políticas públicas atuais no Brasil: o silêncio da educação ambiental, investiga a construção de políticas de EA, que, segundo as autoras, teve expansão na categoria de objeto contemplado por diversas políticas públicas, mas que tem sido desconsiderada pelas políticas de educação nos últimos anos.

É perceptível que pesquisadores têm se empenhado em estudar a EA no ensino básico nos últimos quatro anos, confirmando que o tema ainda está na 
pauta das discussões, abordando concepções de docentes sobre EA, dificuldades relacionadas à implementação da EA no ensino formal, limitações na formação docente, repercussão das políticas de EA no país e abordagem da EA nos documentos norteadores da Educação Básica.

Sendo assim, no primeiro momento da pesquisa, foram descritas as perspectivas dos autores sobre a EA, identificando pontos de contato e divergência; no segundo momento, a partir de Bardin (2004), os assuntos mencionados são categorizados e sintetizados para melhor compreensão, discussão e inferência, a saber: representações dos professores sobre EA e suas práticas; inserção da EA crítica na Educação básica e desafios; EA e a formação de professores e EA e políticas educacionais. Por último, a com base na análise dos resultados, são apresentadas algumas considerações sobre a EA no contexto educacional hoje.

\section{EDUCAÇÃO AMBIENTAL: O QUE DIZEM OS AUTORES}

Os estudos envolvendo a EA apresentam uma gama de concepções, com o objetivo de identificar de que maneiras se complementam ou divergem, serão apresentadas as perspectivas dos autores identificados no levantamento bibliográfico.

No que diz respeito à EA, Pinho et al. (2017) destacam a importância da formação do sujeito ecológico na superação dos desafios oriundos dos problemas socioambientais contemporâneos. Nessa perspectiva, os autores defendem, tendo em vista as considerações de Carvalho (2012), uma educação que possibilite ao sujeito novas formas de ver ou ler o ambiente, para interpretá-lo em toda sua dimensão. Nesse contexto, o professor é entendido como intérprete, mediador, tradutor de mundos. Nesse mesmo raciocínio, os autores mencionam Leff (1999), entendendo a produção do conhecimento na EA como processo dialético em confronto com a realidade e no diálogo com o outro.

Após leitura do estudo de Araújo e Lamim-Guedes Júnior (2017), identificou-se que a percepção dos autores sobre EA vai ao encontro com a de Pinho et al. (2017). Entretanto, Pinho et al. (2017) denunciam representações de EA voltadas somente à conscientização no sentido de preservação da natureza e instrução/informação, enfatizando questões ecológicas. Os autores defendem a EA transformadora, que engloba questões culturais, políticas, econômicas, sociais e históricas, voltada para a construção de valores. Em suas palavras, a EA transformadora "se distingue de tendências politicamente conservadoras que dissociam o social do ambiental, pois afirma a educação como uma práxis 
social e amplia o conceito de ambiente para além dos aspectos físico-biológicos" (PINHO et al., 2017, p. 301).

Sobre o assunto, é importante mencionar as considerações apresentadas no estudo de Figueira, Lima e Selles (2018), que evidenciam as diversas correntes da EA, sintetizadas em: conservacionista, pragmática e crítica. A macrotendência conservacionista "valoriza a dimensão afetiva na relação homem-natureza e a mudança de comportamentos e atitudes individuais" e a EA pragmática, por sua vez, "se concentra em pautas como reciclagem, energia limpa, pegada ecológica etc., e não realiza um aprofundamento de ordem política" (FIGUEIRA; LIMA; SELLES, 2018, p. 357).

Assim sendo, quanto à EA crítica, Figueira, Lima e Selles (2018) entendem para além da visão conservacionista, preocupada com mudança de comportamento, atitudes e valores. Portanto, complementam e superam a perspectiva de Pinho et al. (2017), uma vez que a perspectiva crítica defendida por Figueira, Lima e Selles (2018) vai além quando procura questionar e combater a estrutura de classes na qual tais valores são produzidos e disseminados, isto é, por meio de discussão sociopolítica. Nessa linha de pensamento, a EA crítica não só considera os valores, dentre eles a equidade, justiça social, ética e inclusão, como também valoriza os saberes tradicionais a partir do diálogo entre as diferentes culturas e entre cultura e ciência (FIGUEIRA; LIMA; SELLES, 2018).

O estudo de Mota (2017) denuncia os saberes fragmentados e compartimentalizados, ao defender que os conceitos, vivências, discursos e desafios ambientais se interligam, diferente do que ocorre nas concepções tradicionais de ensino. O autor defende a importância da reflexão crítica, capaz de mobilizar "ações de intervenção sobre as dinâmicas estabelecidas e constituintes da realidade socioambiental" (MOTA, 2017, p. 66). Então, menciona a EA crítica e emancipatória, mas mantém seu enfoque, baseado em Leff (1999), na formação de profissionais capazes de intervirem nas ações cotidianas, visando a mudança de atitudes.

Aragão (2016) fundamenta sua discussão na EA crítica, que põe em pauta a discussão sobre a EA desvinculada da reflexão sobre as políticas educacionais em curso e os rumos do desenvolvimento nacional. Além disso, menciona aquelas práticas corriqueiras voltadas à EA pontual, por meio de atividades disciplinares desarticuladas da vida experiencial, sobretudo sem o desenvolvimento da consciência crítica. Nas palavras do autor: "a EA é em termos práticos um processo político ideológico e social, e não um mero produto, das relações do Homem com o meio natural" (ARAGÃO, 2016, p. 273). Na mesma perspectiva, Frizzo e Carvalho (2018) entendem que a EA não é a educação para o desenvolvimento 
sustentável, focando somente no meio ambiente, mas a valorização da EA que garante o direito à educação como princípio fundamental da formação humana.

Araújo e Oliveira (2017) também seguem a mesma linha de pensamento ao defender uma EA que zele pela contextualização, o diálogo, a criticidade e a complexidade. Ao fazer crítica aos processos formativos centrados na transmissão de conhecimentos prontos por meio de aulas expositivas, os autores acreditam na EA voltada para a transformação e o despertar da criticidade dos alunos. Nesse sentido, defendem a EA voltada para uma perspectiva socioambiental, na qual os professores sejam os "mediadores de um processo de diálogo e reflexão que considere a complexidade das relações socioambientais e contemple os fatores políticos, econômicos, éticos e culturais" (ARAÚJO; OLIVEIRA, 2017, p. 222). Dessa forma, uma educação voltada para o desenvolvimento de uma consciência ecológica, capaz contextualizar questões como: "padronização cultural, à exclusão social, a concentração de renda, às relações de trabalho, ao mercado e à alienação" (ARAÚJO; OLIVEIRA, 2017, p. 222).

Por fim, a perspectiva de Branco, Royer e Branco (2018) e que complementa as demais aqui apresentadas, sobretudo quando os autores entendem a EA como fundamental para conduzir novos pensamentos e práticas, isto é, quebrando alguns paradigmas sociais, formando, sobretudo, cidadãos conscientes e ativos, transcendendo a ideia limitada, reduzida somente ao meio ambiente, tendo em vista também questões econômicas, ideológicas, de justiça, qualidade de vida, cidadania e igualdade.

\section{SÍNTESE DAS PESQUISAS E DISCUSSÃO DOS RESULTADOS}

A fim de sintetizar, discutir e inferir sobre os resultados dos estudos selecionados, foram propostas categorias para sistematizar os dados. $\mathrm{Na}$ primeira categoria, identificada como as representações dos professores sobre EA e suas práticas, foram reunidos os estudos que objetivaram compreender as representações de docentes sobre EA e suas práticas no contexto educacional. A segunda reflete sobre estudos que trataram da inserção da EA crítica na educação básica e seus desafios. A terceira categoria, por sua vez, menciona um estudo que visa refletir a respeito da EA e a formação continuada de professores. Por último, a quarta categoria é representada por estudos que analisam a EA a partir das políticas educacionais brasileiras.

Na primeira categoria, encontram-se as publicações de Pinho et al. (2017) e Araújo (2017). A pesquisa de Pinho et al. (2017) foi realizada por meio de entrevista, com 12 professores de duas turmas do Ensino Fundamental, $6^{\circ}$ e $9^{\circ}$ 
ano. Dentre as questões levantadas no estudo, os autores buscaram compreender quais as temáticas trabalhadas pelos docentes pesquisados, sendo destacadas três: impactos ambientais, conservação dos recursos naturais e reciclagem e coleta seletiva. A metodologia que contemplasse algum assunto relacionado a questões ambientais foi mencionada por 8 professores como sendo expositiva/dialogada com ênfase na informação e sensibilização à preservação, os demais responderam de forma confusa. Nesse âmbito, os autores identificam que 68\% dos docentes descreveram propostas voltadas à informação e sensibilização.

Pinho et al. (2017) também consideraram importante identificar o grau de conhecimento dos docentes sobre os documentos de políticas públicas voltadas à EA no Brasil. Dos entrevistados, 75\% dos professores afirmaram não ter conhecimento sobre as Diretrizes Curriculares Nacionais para a EA. Como instrumento de referência para compreensão das políticas públicas sobre a questão ambiental, encontram-se os PCNs com percentual de 76\%. Como meio de obtenção de informações, 92\% utilizam veículos de comunicação de massa, as mídias.

No que se refere à representação dos docentes sobre EA, o estudo de Pinho et al. (2017) evidenciou que 67\% dos professores a representam como sendo preservacionista-conscientizadora-adestradora. Segundo os autores, a representação dos entrevistados está voltada para a EA que prioriza a relação homem-natureza, voltada para a conscientização e preservação. A visão instrutiva da EA também é marcante na representação dos docentes, 25\% deles a entendem como ato de informar direcionado ao modo de agir. Somente uma representação foi voltada para a EA transformadora, para a construção de valores, englobando questões sociais.

Segundo Pinho et al. (2017), as representações dos docentes voltadas para a concepção preservacionista-conscientizadora-adestradora são fundamentadas pela representação de ambientes antropocêntricos e naturalistas. Conforme os autores, a "conscientização visa o amparo e proteção da natureza biofísica que precisa de ajuda, pois tem sofrido com as ações predatórias do homem com os recursos naturais" (PINHO et al., 2017, p. 301), legitimando, por conseguinte, a visão do homem como gerenciador do ambiente. Assim, suas metodologias evidenciam uma prática educativa voltada para aulas expositivas, fomentando a preservação do meio ambiente, não implicando em mudanças profundas de valores ou atitudes, mediante reflexão da realidade social, indo de encontro com as proposições dos documentos orientadores da EA que defendem práticas educativas interdisciplinares, contextualizadas e transversais, como os PCNs, o Plano Nacional de Educação Ambiental (PNEA) e as Diretrizes Curriculares Nacionais para a Educação Ambiental (DCNEA). 
Araújo e Oliveira (2017) realizaram sua pesquisa com três professores da rede estadual e um da rede municipal, totalizando quatro entrevistados. As concepções dos docentes sobre EA foram divididas nas categorias: teoria, prática, preservação, conservação, aprender a viver, preparar e orientar o aluno, comportamento e educar para o lixo e o trânsito. As representações dos participantes da pesquisa de Araújo e Oliveira (2017) vão ao encontro das representações apresentadas por Pinho et al. (2017), voltadas para a EA intervencionista, naturalista, comportamental. Para os pesquisadores, essas concepções são de uma EA fragmentada e descontextualizada, que "não contribui para a promoção do debate acerca das relações complexas que há entre o ser humano/sociedade/natureza" (ARAÚJO; OLIVEIRA, 2017, p. 226).

Quanto às práticas de EA por parte dos professores, identificou-se, em ambas as pesquisas que buscaram evidenciar as representações dos docentes sobre EA, que alguns docentes não realizam atividades de EA e, dos que realizam, são práticas pontuais, fragmentadas, descontextualizadas, normalmente voltadas ao ensino disciplinar cartesiano. Diante das conclusões apresentadas pelos autores, é perceptível que há certa tendência, como bem coloca Layrargues (2006), baseada numa visão ecológica profunda ou no ambientalismo pós-materialista, voltada para os valores morais e a ruptura da relação humana com a natureza. Nesse aspecto, comumente, a questão ambiental é empregada fora do campo político, voltada somente para mudanças de comportamentos, minimizando a importância da base material na crise ambiental na qual vivenciamos.

A segunda categoria, inserção da EA crítica na educação básica e desafios, é composta pelos estudos de Figueira, Lima e Selles (2018) e Araújo e LamimGuedes Júnior (2017).

Araújo e Lamim-Guedes Júnior (2017) evidenciam os avanços e institucionalização da EA, marcada no contexto da criação, em 1973, da Secretaria Especial do Meio Ambiente, vinculada ao Ministério do Interior, que teve como continuidade a implementação da Política Nacional do Meio Ambiente (PNMA) e se consolida após a promulgação da PNEA - Lei no 9.795/1999 (BRASIL, 1999). Essas políticas favoreceram o avanço da EA e sua inclusão no ensino formal. No entanto, mesmo com avanços, os autores deixam claro os desafios da EA na atualidade, como: "enfrentar a multiplicidade de visões, superar a visão do especialista, superar a pedagogia das certezas e superar a lógica da exclusão" (ARAÚJO; LAMIM-GUEDES JÚNIOR, 2017, p. 154).

Os desafios apresentados se referem à necessidade de conexão entre a vida e o conhecimento, considerando, sobretudo, a diversidade cultural que proponha a superação da estrutura disciplinar rígida do currículo escolar com o objetivo 
de pensar em alternativas "inter", "multi" e transdisciplinares nesse contexto e romper com o paradigma positivista da pedagogia, repensando, com isso, a epistemologia hegemônica. Além disso, outro desafio apresentado diz respeito ao papel da EA como transformadora, comprometida com a justiça social e ecológica. Apesar das adversidades, os autores citam alguns exemplos de ações bem-sucedidas de EA na educação básica do Brasil, sendo, em alguns casos, a atuação das universidades no processo.

O tema também é abordado no outro artigo da categoria. Figueira, Lima e Selles (2018, p. 359), apontam que, mesmo que algumas escolas adotem a EA, os desafios ainda são significativos, tendo em vista a "formação inadequada ou insuficiente, falta de tempo para a elaboração de projetos, currículos com muitos conteúdos", dentre outros. Uma das sugestões dos autores para enfrentar os desafios em relação à EA, seria a implementação da EA crítica pelo caminho da extensão universitária.

A pesquisa de Figueira, Lima e Selles (2018) foi realizada em duas escolas municipais com professores e professoras que atuam no ensino regular, nas séries iniciais do Ensino Fundamental e Educação Infantil, e na Educação de Jovens e Adultos que participaram do projeto de extensão da Universidade Federal do Rio de Janeiro (UFRJ), voltado para a EA. O projeto dialoga com estudantes universitários, docentes e discentes de escolas públicas, por meio de grupo focal, buscando explorar o potencial e as limitações da EA crítica. Segundo os autores, o projeto influenciou nas visões dos professores sobre a EA, que foram voltadas para o viés socioambiental.

A flexibilidade curricular foi uma das problemáticas levantadas, apresentando-se também como um desafio para trabalhar a EA. No entanto, a atuação do projeto, segundo os autores, deu suporte aos professores para a ampliação das possibilidades de abordagem curricular e influenciou nos modos de repensar o planejamento. Por outro lado, ainda assim mencionam, em alguns casos, as dificuldades de se repensar a prática e o planejamento, diante do desconforto a influências externas, quando não dialogam com a realidade da escola. Por essa razão, os pesquisadores alegam a importância de se considerar a autonomia e o protagonismo dos docentes na atuação dos projetos extensionistas.

Por fim, Figueira, Lima e Selles (2018) demonstram que a interação entre escola e universidade possibilita uma rica troca de saberes, quando, sobretudo, desconstrói a visão hierarquizada e utilitarista das atividades provindas da extensão acadêmica e uma relação de reciprocidade, como via de mão dupla na produção do conhecimento. Quanto à EA, indo além de questões relacionadas às macrotendências envolvendo abordagens pragmática, conservacionista e crítica, 
o estudo evidenciou que os docentes produzem modos específicos de combinálas pedagogicamente para garantir a presença da EA no cotidiano da escola.

Acredita-se, portanto, que o diálogo entre universidade e escola não só pode contribuir para repensar práticas no contexto escolar, como discutir também o currículo, e para o fortalecimento do entendimento da EA na perspectiva mais crítica; assim como servir para estudos universitários sobre as diferentes abordagens e perspectivas da Educação Ambiental nas escolas brasileiras, fato demonstrado pelo trabalho de Figueira, Lima e Selles (2018).

Nessa linha de pensamento, é possível identificar que a falta de entendimento a partir de uma perspectiva crítica de EA é um dos desafios a ser superado nessa área. Araújo e Lamim-Guedes Júnior (2017) mencionam a necessidade de romper com o paradigma positivista da pedagogia, pensando a EA como transformadora. Para isso, é fundamental pôr em questionamento a epistemologia hegemônica. Segundo Layrargues (2006), a EA é, antes de tudo, educação. Como educação, como instituição, a escola se configura em aparelho ideológico que, por sua vez, reproduz as condições sociais. O entendimento da EA na perspectiva crítica é a possibilidade de se pensar a EA que coloque no centro das atenções a sua relação implícita com a mudança social. Nesse caso,

a questão crucial a ser atualmente respondida, portanto, além da eficácia de sua cota de participação na tarefa na reversão da crise ambiental, é se essa prática pedagógica reproduz ou transforma as condições sociais tal qual se encontram atualmente. Em outras palavras: se reproduz os valores, os princípios, os fundamentos e em especial, as relações sociais capitalistas; ou ao contrário, se os transforma (LAYRARGUES, 2006, p. 5).

A efetivação da EA crítica está, dentre outros fatores, fortemente relacionada à terceira categoria deste estudo, que diz respeito à formação de professores. Nessa categoria, está situado o estudo de Mota (2017).

Um dos desafios apresentados pelo autor diz respeito a formações continuadas que geralmente são realizadas de forma desconexa com o contexto cultural e social dos profissionais, sem levar em consideração as reais necessidades dos docentes. Outro fator é a necessidade, tendo em vista a modernidade, do desenvolvimento de novas competências e habilidades, acentuando a necessidade de atualização constante do profissional. No entanto, as dificuldades socioeconômicas, falta de tempo e excesso na carga horária podem se configurar em impasses para a continuidade da formação são indicados no artigo. Dentre esses impasses, o autor também menciona a resistência dos profissionais, a falta de oportunidades e, em alguns casos, a desvinculação dos cursos de formação inicial oferecidos nas Instituições de Educação Superior (IES) no contexto educacional. 
Nesse âmbito, a presença da EA de maneira utilitarista, pontual, fragmentada, geralmente em datas específicas e sobre gestão de resíduos, o desconhecimento e a falta de prática de alguns professores voltadas a ela tornam visível a necessidade de pensá-la inserida na formação dos professores.

Segundo Mota (2017), os próprios PCNs apontam a necessidade de investimento contínuo e sistemático para que o professor se desenvolva enquanto profissional da educação. Além disso, quanto à EA, a PNEA recomenda a incorporação da dimensão ambiental na formação, especialização e atualização dos educadores de todos os níveis de ensino, defendendo que esses professores devam receber formação complementar, visando atingir os princípios e objetivos estabelecidos na referida Lei.

No entanto, mesmo com a crescente oferta de cursos de Ensino Superior, cursos de pós-graduação Lato Sensu e Stricto Sensu na área da EA, a formação do educador ambiental na perspectiva crítica, ainda é, conforme Mota (2017), um processo a ser conquistado e efetivado. Ainda assim, mesmo a legislação assegurando o tratamento de questões ambientais no currículo de formação de professores, a incorporação da EA no Ensino Superior não é tão simples, e depende, conforme Thomaz e Camargo (2007), da capacitação de todos os profissionais participantes, envolvendo, além dos discentes, o docente que irá ministrar a matéria, o qual deverá ter clareza da importância da EA como uma mudança de padrão de pensamento e da importância dos futuros docentes estarem preparados para lidarem com as questões ambientais de uma forma interdisciplinar, para além de temas, datas e eventos comemorativos.

Finalmente, na última categoria, denominada EA e políticas educacionais, encontram-se os estudos de Aragão (2016), Branco, Royer e Branco (2018) e Frizzo e Carvalho (2018).

Segundo Aragão (2016), as políticas de EA são um dado relativamente recente na história da educação no Brasil e sua materialização na educação básica ainda é questionável, tendo em vista as contradições e dificuldades de implementação de duas diretrizes na realidade educacional escolar, dentre elas, a falta de flexibilização curricular que é disciplinar, em detrimento das propostas de interdisciplinaridade e transversalidade contidas na PNEA. Por essa razão, o autor objetivou analisar as políticas de Educação Ambiental no Brasil e suas repercussões sobre o planejamento da educação básica no ensino público, baseado na concepção crítica de EA.

Aragão (2016), apoiado na perspectiva crítica de EA, afirma que:

Existe um juízo sobre as políticas públicas de Educação Ambiental que aponta a produção de ações transformadoras que colaborem na prevenção 
e enfrentamento dos desafios globais, apoiadas numa governança democrática mais intensa, que estimule uma cidadania reflexiva. Aprender a encarar as ameaças numa sociedade capitalista implica na criação de espaços de interlocução para novas formas de participação política e experiência da vida democrática conduzidas a partir do cotidiano e não das bancadas jurisdicionais (ARAGÃO, 2016, p. 216).

Mesmo com argumentos que defendem o desenvolvimento satisfatório das políticas de EA, Aragão (2016) afirma que as políticas públicas de EA não atendem às demandas da sociedade, especialmente no contexto da educação básica, e menciona as contradições por parte do Estado no que se refere à implementação e avaliação dessas políticas no âmbito concreto. Conforme o autor, essas políticas partem de ações que não consideram problemas históricos da educação escolar e seus mecanismos de exclusão e são concebidas distante da realidade escolar, isto é:

[...] são pensadas de um ponto tão alto do céu que, ao se aproximarem da superfície terrena, onde estão nossas escolas, sua luz já fosse tão fraca, que por consequência, as interpretações de professores, gestores e funcionários são tão limitadas que a ideia de uma Educação Ambiental e Interdisciplinar é dissolvida (ARAGÃO, 2016, p. 269).

Aragão (2016) chamou esse processo de setorialismo educacional, que dicotomiza os professores, dividindo entre universitários e escolares. Os professores das escolas municipais e estaduais, nesse caso, têm suas práticas comprometidas pela falta de tempo para a pesquisa e extensão, pela ausência de participação na operacionalidade das políticas públicas, dentre outras questões.

O insucesso das políticas de EA pode estar ligado a questões estruturais da sociedade e que só "repensando o modelo de sociedade, bem como as políticas umbilicalmente geradas neste modelo que será possível reformar as formas de pensar e fazer a educação" (ARAGÃO, 2016, p. 70). Essa questão não é possível quando o modelo de educação se apoia da ideia de formação de capital humano a serviço do sistema de produção "realizando um desenvolvimento que antes da emancipação do homem, da instrumentalização enquanto cidadão, gera em mão única e perversa, sua má inclusão na sociedade de consumo pré-fabricada" (ARAGÃO, 2016, p. 270). Esse insucesso se materializa por meio das práticas corriqueiras e disciplinares de EA, sem considerar a transformação da consciência crítica dos indivíduos, desarticuladas da vida, ou a implementação da EA como disciplina específica no currículo, contrariando as diretrizes da PNEA que indicam, dentre outras, a transversalidade, continuidade e permanência da EA. 
Ainda sobre políticas educacionais, Branco, Royer e Branco (2018) investigaram acerca da legislação na área ambiental e as abordagens da EA no currículo da educação básica no Brasil, a partir de análise dos documentos como os PCNs e DCNs. A BNCC também foi analisada na hipótese de saber se o documento sugere mudanças e fomenta o ensino da Educação Ambiental como mecanismo para superar dificuldades, injustiças e exploração do meio ambiente.

Conforme Branco, Royer e Branco (2018), é importante levar em consideração que, mesmo com os avanços da EA no contexto educacional brasileiro, não há garantia no cumprimento dos documentos legais.

Como mencionado, os PCNs abordam a questão da EA desenvolvida em todas as áreas da Educação Básica de maneira transversal e interdisciplinar. Segundo Branco, Royer e Branco (2018, p. 195):

Embora a Educação Ambiental seja contemplada de forma diluída no currículo, é destacada, no caderno Ciências Naturais, fortalecendo certa crença de que se trata de um assunto de maior responsabilidade para esta disciplina, reforçando o caráter de preservação e exploração "consciente" sobre a natureza, de maneira que o desenvolvimento e a sustentabilidade se justifiquem sob a égide de "menor degradação possível" ao meio, ao homem e a vida.

No entanto, os autores questionam se os PCNs foram úteis no sentido de viabilizar a EA semelhante à apresentada na legislação e se forneceram a formação/instrução básica aos professores para tal ensino. Da mesma, a EA é contemplada nas DCNs, no entanto, o caráter não obrigatório do documento como norteador da educação básica possibilitou diferentes interpretações e metodologias, configurando-se em uma pluralidade na organização curricular de todo o país (BRANCO; ROYER; BRANCO, 2018).

Já a BNCC, embora não aborde diretamente a Educação Ambiental, em sua primeira versão, reforça conceitos relacionados à preservação do meio ambiente, consumismo e sustentabilidade, abordados a partir de temas transversais. $\mathrm{Na}$ segunda versão do documento, a EA é apresentada como:

uma dimensão da educação escolar, uma atividade intencional da prática social que deve imprimir no desenvolvimento individual, um caráter social em sua relação com a natureza e com os outros seres humanos. Segundo apresenta, objetiva a construção de conhecimentos, desenvolvimento de habilidades, atitudes e valores, o cuidado com a qualidade de vida, a justiça e a equidade socioambiental e a proteção do meio ambiente natural e construído (BRANCO; ROYER; BRANCO, 2018, p. 197). 
Para isso, a prática pedagógica de EA deve adotar um caráter crítico, considerando as dimensões envolvendo natureza, social, produção, trabalho e consumo, para além da visão naturalista.

Em sua segunda versão, a BNCC situa a EA como tema especial, considerando também questões socioambientais a partir de debates e reflexões acerca da desigualdade, produção não sustentável e consumo. No entanto, na terceira versão do documento, disponibilizada para as etapas da Educação Infantil e do Ensino Fundamental, o termo EA não é contemplado, assim como na primeira versão. Branco, Royer e Branco (2018) evidenciam que, da primeira para a segunda versão, houve um aumento significativo de dados e páginas em relação à EA, mas, da segunda para a terceira versão (versão final), não só a quantidade de páginas diminuiu, como também a abordagem [o aprofundamento] sobre o tema.

Com relação à versão final da BNCC, Branco, Royer e Branco (2018) afirmam que predomina a ênfase na sustentabilidade, voltada para o uso dos recursos naturais do meio ambiente. Nesse sentido, o termo EA propriamente dito não aparece no documento, que a considera enquanto determinadas habilidades ou aprendizagens essenciais.

Tanto nos PCNs e DCNs quanto na BNCC, a EA prevalece como tema transversal sobre o discurso de instigar a repensar novas práticas, valorização da relação homem-natureza e questões envolvendo a sustentabilidade. No entanto, mesmo que a EA seja reconhecida como elemento não disciplinar, pouco tem se concretizado efetivamente nas escolas e na formação de professores, persistindo a prática que "destoa da teoria, evidenciando quando não há apropriação do conhecimento esperado e condições mínimas para efetivar-se" (BRANCO; ROYER; BRANCO, 2018, p. 200), chegando à conclusão de que os documentos foram insuficientes para nortear a EA crítica e satisfatória e que a BNCC, norma mais atual, não apresenta nenhuma mudança significativa para o fortalecimento da Educação Ambiental no cenário nacional.

Na mesma ótica, Frizzo e Carvalho (2018) buscaram analisar políticas educacionais federais, que, segundo as autoras, inicialmente valorizaram a EA, mas que têm sido preteridas nos últimos anos, especificamente por meio de certa exclusão do tema dos principais documentos recentes que embasam e regulam as instituições escolares. Nesse sentido, as autoras partem da seguinte questão: "de que forma e por que as políticas púbicas atuais têm silenciado a educação ambiental e como se deu esse processo?" (FRIZZO; CARVALHO, 2018, p. 117).

De acordo com Frizzo e Carvalho (2018), foi na década de 2000 e 2010 que a EA ganhou força e avançou com relação à sua inserção nos currículos e em programas voltados para a escola, dentre eles, o programa lançado pelo 
Ministério da Educação (MEC) em 2001, denominado "Programa Parâmetros em Ação: meio ambiente na escola", além de outros programas, grupos e comissões voltadas à EA. Ainda sobre as conquistas, a EA ganhou espaço com as Diretrizes Curriculares Nacionais para a Educação Ambiental, e sua obrigatoriedade na LDB. Porém, a obrigatoriedade foi retirada em 2016 com a Medida Provisória ${ }^{\circ}$ 746 (BRASIL, 2016). O fato de muitos programas passarem por modificações ou serem revogados está relacionado, conforme Frizzo e Carvalho (2018), com as mudanças de governo e ministérios.

É perceptível, conforme os apontamentos de Frizzo e Carvalho (2018), o silenciamento da EA nas políticas públicas, dentre elas, o Plano Nacional de Educação (PNE) de 2014 e a BNCC, analisados pelas autoras. Após leitura dos documentos que antecedem o PNE, oriundos da Conferência Nacional de Educação (CONAE, 2010-2014), as autoras identificaram certa descontinuidade com relação à EA, que, apesar de referências reiteradas para o tema, o Plano não correspondeu às expectativas.

Quanto à BNCC, em conformidade com Branco, Royer e Branco (2018), Frizzo e Carvalho (2018) também evidenciam que a educação ambiental, que não era contemplada no primeiro documento, apareceu com frequência na segunda versão, sendo eliminada por completo na terceira versão. De acordo com Frizzo e Carvalho (2018), a EA é citada somente nos comentários, no que se refere às possibilidades para o currículo, no entanto, não é contemplada como "objetos de conhecimento".

Dos 64 especialistas indicados/solicitados pelo MEC em 2016, a fim de elencar seus pareceres críticos em relação à BNCC, somente sete faziam referência à EA, observando a falta de abordagem da EA crítica e emancipatória, da reflexão sobre a questão ambiental e suas causas, bem como a falta de conceituação teórica sobre sustentabilidade ambiental e socioambiental, elementos que apareceram no documento.

Ainda que o termo EA tenha sido consolidado no Brasil, esse parece ter perdido destaque tanto nas políticas públicas, quanto nos eventos nacionais e internacionais, dentre eles, os encontros da Assembleia Ambiental das Nações Unidas em 2014 e 2016, que deram ênfase e reforçaram a ideia de desenvolvimento sustentável. No que diz respeito às políticas públicas atuais, há maiores "investidas na proposta de sustentabilidade, de desenvolvimento sustentável e de educação para a sustentabilidade do que de educação ambiental" (FRIZZO; CARVALHO, 2018, p. 124).

Dentre os retrocessos apresentados no decorrer deste estudo, destaca-se a tendência atual de enfocar em desenvolvimento sustentável. Sobre o assunto, 
Carvalho (2002) afirma que a renomeação do conceito de EA, geralmente substituído por "educação para o desenvolvimento sustentável” ou "educação para a sustentabilidade", evidencia a disputa ideológica por sentidos históricos, políticos e identitários, nesse caso, com base no ideário desenvolvimentista.

A reflexão sobre os ideários que subjazem o conceito de EA, empregado nos documentos atuais, é imprescindível, tendo em vista que, em muitos casos, a EA serve como instrumento de atualização ideológica da hegemonia. Por essa razão, deve-se transcender a ideia de EA que visa somente a criação de uma consciência ecológica, afinal, "só é possível se instaurar uma nova ética, a ecológica, se ao mesmo tempo se instaurar uma nova relação social, que não seja mediada (exclusivamente pelo menos) pelo capital" (LAYRARGUES, 2006, p. 9). Em outras palavras, a humanidade enfrenta a exploração da natureza quando enfrenta a exploração do ser humano pelo ser humano.

Assim sendo, Layrargues (2006) defende a educação ambiental que integra, ao mesmo tempo, a construção de uma sociedade ecologicamente equilibrada, culturalmente diversa, socialmente justa e politicamente atuante. O papel do educador ambiental, nesse sentido, consiste em romper com a opressão da violência simbólica acometida pela ideologia hegemônica que sobrepõe a dimensão ética sobre a política, os valores sobre os interesses, e que se concentra na mudança cultural, silenciando a sua participação na mudança social (LAYRARGUES, 2006, p. 11, grifos do autor).

Isso será possível na medida em que seja superada a despolitização da educação, visando, juntamente com a criação da consciência ecológica, a criação de uma consciência política, ou seja, uma educação ambiental que "enfrenta o desafio da complexidade, porque os problemas ambientais acontecem como decorrência de práticas sociais, e como tal, expõem grupos sociais em situação de conflito socioambiental" (LAYRARGUES, 2006, p. 3).

\section{CONSIDERAÇÕES FINAIS}

A análise das percepções dos autores dos textos selecionados mostrou-se importante nesse processo, principalmente para entender em quais perspectivas de EA estão embasados. Evidente está que grande maioria se apoia na discussão sobre uma EA crítica, entendendo-a como fundamental para conduzir novos pensamentos e práticas, a partir da transformação social.

Os autores denunciam concepções reduzidas, fragmentadas, pontuais, voltadas somente à natureza e defendem a necessidade de transpor alguns paradigmas sociais, formando cidadãos conscientes e ativos, considerando 
questões econômicas, ideológicas, de justiça, qualidade de vida, cidadania e igualdade social.

Além disso, o estudo foi importante no sentido de compreender, através das pesquisas já realizadas, o lugar da EA no contexto educacional hoje. Como resposta, percebeu-se que a EA, principalmente na perspectiva crítica, ocupa uma posição discreta na prática pedagógica e no contexto educacional como um todo, quando não, inexistente.

Compreender a representação de EA dos docentes que atuam na Educação Básica é basilar para entendermos um dos fatores relacionados à discrição da EA hoje. Conforme as pesquisas aqui sintetizadas, comumente os professores se apoiam em um entendimento preservacionista, conscientizador e instrutivo de EA, pautados em temas e terminologias corriqueiros, comum nos discursos atuais, tais como: reciclagem do lixo, preservação da água, desenvolvimento sustentável, dentre outros. São temas triviais quando não compreendidos em sua dimensão complexa.

A EA transcende a ideia de que visa a criação de uma consciência ecológica, tendo em vista que, antes, é fundamental a consciência de justiça socioambiental. Portanto, é um processo dialético de desenvolvimento da consciência ecológica e política. É, antes de tudo, educação. É educar para a mudança, cultural e social.

Portanto, a urgência de problematizar as representações dos professores sobre EA deve ser acentuada. Isso porque, longe de culpá-los, ao problematizá-las, coloca o sistema nas quais são criadas no cerne das discussões. Explicitamente, os estudos apontam para a insuficiência na formação dos professores a respeito da EA, necessidade do diálogo entre a universidade e a escola como via de formação continuada e a redução da abordagem nas Leis e documentos que norteiam a educação brasileira.

Ainda assim, dentre os retrocessos apresentados, há uma tendência atual de enfocar no desenvolvimento sustentável que precisa estar no eixo das discussões. Como mencionado, a escola é uma instituição favorável como via de reprodução e atualização da ideologia hegemônica, hoje, baseada exclusivamente no princípio neoliberal. Portanto, as Leis e práticas voltadas para a educação não são neutras. Com o discurso de educação para o desenvolvimento sustentável ou para a sustentabilidade, podem camuflar intenções com ideário desenvolvimentista.

Por essas e outras razões, a EA na perspectiva crítica e emancipatória tem urgência por uma educação que irrompa com o modelo vigente, desigual e destrutivo, tendo em vista que os problemas ambientais decorrem das práticas sociais. A sociedade está fadada a reproduzir ou transformar as condições sociais. $\mathrm{Na}$ escola, a hegemonia dominante será reproduzida ou transformada. 
A conclusão do presente estudo fecha na certeza de que questões referentes à EA, especificamente na Educação Básica, precisam continuar na pauta das discussões que permeiam as políticas educacionais. A função social da escola está clara nos documentos, que garantem, como princípio da educação básica, o pleno desenvolvimento do educando, seu preparo para o exercício da cidadania e sua qualificação para o trabalho. No entanto, aparenta que até o papel social da escola hoje está envolto em certa nebulosidade. Atualmente, tendo em vista o ideário desenvolvimentista que subjaz a educação e a maior ênfase atribuída ao mercado de trabalho, há que se questionar: que tipo de cidadão estamos falando? Qual o lugar da EA no contexto da Educação Básica hoje? Ou melhor, qual a função social da Educação Ambiental hoje? Eis algumas proposições para futuras pesquisas.

\section{REFERÊNCIAS}

ARAGÃO, J. P. G. As políticas de Educação Ambiental e suas repercussões sobre o planejamento da educação básica no ensino público brasileiro. Revbea, São Paulo, v. 11, n. 2, p. 263-278, 2016.

ARAÚJO, A. F.; OLIVEIRA, M. M. Concepções e atividades docentes de Educação Ambiental e seus desdobramentos na formação de alunos da educação básica. Rev. Eletrônica Mestr. Educ. Ambient., Rio Grande, v. 34, n.1, p. 217-232, jan./abr., 2017. Disponível em: https://periodicos.furg.br/ remea/article/view/6675. Acesso em: 10 mar. 2020.

ARAÚJO, J. P. G.; LAMIM-GUEDES JUNIOR, V. Uma breve reflexão sobre os desafios da Educação Ambiental no ensino formal Brasileiro. Revista

Científica RUNAE, Azogues, v. 1, n. 1, p. 149-165, fev. 2018. Disponível em: http://runae.unae.edu.ec/revistas3/index.php/RUNAE/article/view/46.

Acesso em: 10 mar. 2020.

BARDIN, L. Análise de conteúdo. Lisboa: Edições 70, 2004.

BRANCO, E. P.; ROYER, M. R.; BRANCO, A. B. G. A abordagem da educação ambiental nos PCNs, nas DCNs e na BNCC. Nuances, Presidente Prudente, v. 29, n. 1, p.185-203, jan./abr. 2018. Disponível em: http:/ / revista. fct.unesp.br/index.php/Nuances/article/view/5526. Acesso em: 10 mar. 2020.

BRASIL. Lei n. 9.795, de 27 de abril de 1999. Dispõe sobre a Educação Ambiental [...]. Brasília, DF: Presidência da República, [1999]. Disponível em: http:/ /www. planalto.gov.br/ccivil_03/LEIS/L9795.htm. Acesso em: 10 de fev. de 2020. 
BRASIL. Diretrizes Curriculares Nacionais da Educação Básica. Brasília, DF: MEC: SEB: DICEI, 2013. 562 p.

BRASIL. Medida Provisória n. 746, de 2016. Institui a Política de Fomento à Implementação de Escolas de Ensino Médio em Tempo Integral, altera a Lei n ${ }^{\circ}$ 9.394, de 20 de dezembro de 1996 [...]. Brasília, DF: Presidência da República, [2016]. Disponível em: https://www.congressonacional.leg.br/materias/ medidas-provisorias/-/mpv/126992\#: :text=Determina \%20que\%20o\%20 ensino $\% 20$ de, as $\% 20$ facultativas $\% 20$ no $\% 20$ ensino $\% 20 \mathrm{~m} \% \mathrm{C} 3 \%$ A 9 dio. Acesso em: 10 fev. 2020.

CARVALHO, I. C. M. O “ambiental” como valor substantivo: uma reflexão sobre a identidade da educação ambiental. In: SAUVÉ, L.; ORELLANA, I.; SATO, M. (org.). Textos escolhidos em educação ambiental: de uma América à outra. Montreal: ERE-UQAM, 2002. p. 85-90.

CARVALHO, I. C. M. Educação ambiental: a formação do sujeito ecológico. 6. ed. São Paulo: Cortez. 2012.

FIGUEIRA, M. R.; LIMA, M. J. G. S.; SELLES, S. L. E. A inserção da Educação Ambiental crítica na escola via extensão universitária. Rev. Espaço do Currículo, João Pessoa, v. 11, n. 13, p. 356-369, set./dez. 2018. Disponível em: https://periodicos.ufpb.br/index.php/rec/article/view/ufpb.19831579.2018v3 n11.42077. Acesso em: 09 mar. 2020.

FRIZZO, T. C. E.; CARVALHO, I. C. M. Políticas públicas atuais no Brasil: o silêncio da educação ambiental. Rev. Eletrônica Mestr. Educ. Ambient., Rio Grande, Ed. Especial EDEA, n. 1, p. 115-127, 2018. Disponível em: https:/ / periodicos.furg.br/remea/article/view/8567. Acesso em: 10 mar. 2020.

LAYRARGUES, P. P. Muito além da natureza: Educação Ambiental e reprodução social. In: LOUREIRO, C. F. B.; LAYRARGUES, P. P.; CASTRO, R. C. (org.) Pensamento complexo, dialética e educação ambiental. São Paulo: Cortez, 2006. p. 72-103.

LEFF, E. Educação ambiental e desenvolvimento sustentável. In: REIGOTA, M. (org.). Verde cotidiano: o meio ambiente em discussão. Rio de Janeiro: DP\&A, 1999. p. 111-129.

MOTA, J. C. Formações continuadas em educação ambiental: características e limitações. Revista Espaço Acadêmico, Maringá, v. 17, n. 192, p.59-68, maio 2017. Disponível em: http://www.periodicos.uem.br/ojs/index.php/ EspacoAcademico/issue/view/1209. Acesso em: 10 mar. 2020. 
PINHO, M. F. M. et al. Representações de ambiente e educação ambiental: implicações na práxis educativa de professores de ensino fundamental em Moju, PA. Terræ Didatica, Campinas, v. 13, n. 3. p. 295-302, set./dez. 2017. Disponível em: http://www.ige.unicamp.br/terraedidatica/. Acesso em: 09 mar. 2020.

THOMAZ, C. E.; CAMARGO, D. M. P. Educação ambiental no ensino superior: múltiplos olhares. Revista Eletrônica do Mestrado em Educação Ambiental, Rio Grande, v. 18, p. 303-318, jan./jun. 2007. Disponível em: http://www.remea.furg.br. Acesso em: 06 fev. 2020. 